\title{
Android Based Self-Control Management System for Diabetes Mellitus
}

\author{
Devi Astri Nawangnugraeni ${ }^{1}$, R. Rizal Isnanto $^{2}$, and Oky Dwi Nurhayati ${ }^{2}$ \\ ${ }^{1}$ Master Program of Information System, School of Postgraduate Studies, Diponegoro University, Semarang - \\ Indonesia \\ ${ }^{2}$ Department of Computer Engineering, Faculty of Engineering, Diponegoro University, Semarang - Indonesia
}

\begin{abstract}
One of the biggest cause of death is Diabetes Mellitus caused by a lack of public understanding of the symptoms of the disease, so that the diagnosis of the disease is not done as early as possible. This paper presents the research and the development of an Android based self-control management expert system for Diabetes Mellitus patients. This expert system purposed to diagnose Diabetes Mellitus disease based on symptoms experienced and to manage the dietary pattern in patients. The method used to develop expert system is forward chaining method. Implementation of the forward chaining method begins with gathering information then applying reasoning as a determinant of diagnosis conclusions using rule based If-Then. The development result is an expert system that can be used to diagnose Diabetes Mellitus and can be used to determine the dietary pattern in patients who are implemented on Android based mobile devices. This system shows more specific results in determining the diagnosis of the disease based on 4 types of Diabetes Mellitus. In addition, more specific in determining dietary pattern such as showing the number of calories, food levels and variations of food that can be consumed by patients.
\end{abstract}

Keywords: Expert system, Diabetes mellitus, Dietary pattern, Android, Forward Chaining

\section{Introduction}

Currently expert system implementation has been widely used in the field of health. This system is used as a storage of expert knowledge in computer programs so that decisions can be given with intelligent reasoning. One of the implementation of expert systems in the field of health is to diagnose symptoms in patients with Diabetes Mellitus [1]. In the expert system of diagnosis of symptoms of Diabetes Mellitus can be analyzed using the forward chaining method commonly utilized both for forecasting and controlling problems. It is the search method for gathering the existing information and combining the rules in order to find the object and conclusion. [2].

The development of expert system in health can be applied to a mobile device application. Use of applications on mobile devices can also be used as a selfcontrol management in Diabetes Mellitus patients [3]. The application can be implemented on various platforms like Android, Windows Phone or iOS. One is the use of mobile devices with the Android platform that can be used as a healthy control device [4].

The right ability to analyze symptoms is important in preventing Diabetes Mellitus, thereby reducing the risk of complications caused by Diabetes Mellitus. Therefore, management or management of Diabetes Mellitus is necessary. As a preliminary check and selfcontrol management can be done with the help of expert systems. Detection can be implemented in mobile device applications, either with Android platform, Windows Phone or iOS.

The development of expert system apps on Android mobile devices previous has been developed on Google Play. However, in the application is only used as a risk check for Diabetes Mellitus and patient medical records only, there is no feature calculation of caloric needs for dietary patterns in Diabetes Mellitus patients.

To overcome the weakness of the previous system, then developed an expert system that can run on the Android mobile device as a self-control management application. This system is implemented in Diabetes Mellitus patients using forward chaining method.

\footnotetext{
* Corresponding author: devinawang4@gmail.com
} 


\section{Literature review}

\subsection{Expert System}

Expert system to be developed are categorized into two, such as expert system support detection Diabetes Mellitus disease based on Android that can be used to detect Diabetes Mellitus from symptoms experienced by patients using Android mobile devices, Expert system management dietary pattern of Diabetes Mellitus patients based on Android that can be used to calculate the number of calories and support determination of food that can be consumed by patients using Android mobile devices.

Expert system are knowledge-based programs that provide solutions with expert knowledge standards to solve problems within a specific domain. Expert system are also developed on the basis of knowledge and rules because the problems encountered by an expert are solved based on the knowledge, rules and experience [2]. Implementation of expert systems are widely used in various fields one of them is the field of health to detect a symptom or type of Diabetes Mellitus disease [1]. Expert system can also be used for medical consultations or diagnostic consultations. The advantages of using an expert system are fast, cost saving, improved quality, save on working time and have reliable information [5].

The development of expert system in health can be applied to a mobile device application, which is used as a self-control management in Diabetes Mellitus patients [3]. The application can be implemented on various platforms like Android, Windows Phone or iOS. One is the use of mobile devices with the Android platform as a health control device [4].

\subsection{Diabetes Mellitus}

Diabetes Mellitus (DM) is defined as a chronic disease or disorder with multiple etiologies characterized by high blood sugar levels with carbohydrate, lipid and protein metabolism disorders as a result of insulin function insufficiency [6]. Diabetes desease is able to be classified into 4 categories, such as Type 1 Diabetes Mellitus, Type 2 Diabetes Mellitus, Specific types of Diabetes Mellitus due to other causes, and Gestasional Diabetes Mellitus [7]. Symptoms of Diabetes Mellitus is shown in Table 1 [8]. As a chronic disease, diabetes is associated with other disease complications. Collection of glucose in the bloodstream or hyperglycemia causes complications of other diseases. However, these complications can be overcome by self-control management is done regularly and well. Self-control management of Diabetes Mellitus disease is a very important thing done by patients, because patients can monitor their health. Self-control can be done with medication, diet, exercise and monitoring blood sugar levels [9]. Diet in patients aims to lower sugar in the urine, achieve normal weight, optimal nutritional status, and prevent diabetes complications [10-12].

\section{Method and design}

\subsection{Assesment}

Assessment of the state is the first stage, that is explaining the problems or needs of the object, determine the solution of the problem, determine the expert and determine the method used. Objects in the development of this expert system of Diabetes Mellitus disease diagnosis based on symptoms experienced by patients and the determination of the number of calories for the patient's diet. Based on these symptoms the expert system can be used as a support system in determining the type of Diabetes Mellitus disease and determine the diet pattern of the patient. Experts to determine the decision on the expert system is the Internists and Nutritionists. The method used for decision making on expert system is forward chaining method.

\subsection{Knowledge Acquisition}

Knowledge acquisition is the second stage, which is to search information in the form of disease data, knowledge of artificial intelligence and expert system to determine the decision. It then represents knowledge, build the knowledge base, validates knowledge, and creates the decision table. Data of Diabetes Mellitus symptoms can be shown in Table 1 [8]. Based on symptoms data it can be made a decision table and production rules to determine the type of Diabetes Mellitus disease. The Decision Table is shown in Table 2 and the production rules are shown in Table 3.

Table 1. Symptoms of Diabetes Mellitus

\begin{tabular}{|l|l|}
\hline Disease Name & \multicolumn{1}{|c|}{ Symptoms and Code } \\
\hline $\begin{array}{l}\text { Type 1 } \\
\text { Miabetes }\end{array}$ & \begin{tabular}{l} 
Often thirsty (G01), often hunger \\
(G02), often urination (G03), \\
weight loss (G04), age between 0- \\
14 years (G05), fatigue (G06), \\
blurred eyes (G07), pin and \\
needles (G08), hives (G09), ulcers \\
purulent boils (G10), impotence \\
(L)/vaginal discharge (P) (G11), \\
infection (G12), family offspring \\
Diabetes Mellitus (G13) \\
\hline Gestational \\
$\begin{array}{l}\text { Often thirsty (G01), often hunger } \\
\text { Mellitus (P02) }\end{array}$ \\
$\begin{array}{l}\text { W0ight often urination (G03), } \\
\text { pregnancy (G14), increased blood }\end{array}$ \\
sugar levels during pregnancy \\
(G15), has a history of giving birth \\
to a large baby (G16), dry lip \\
mucosa (G17) fatigue (G06), \\
blurred eyes (G07), vaginal
\end{tabular} \\
\hline
\end{tabular}

\footnotetext{
Corresponding author: devinawang4@,gmail.com
} 


\begin{tabular}{|l|l|}
\hline Disease Name & \multicolumn{1}{|c|}{ Symptoms and Code } \\
\hline $\begin{array}{l}\text { Type 2 } \\
\text { Diabetes } \\
\text { Mellitus (P03) }\end{array}$ & $\begin{array}{l}\text { Often thirsty (G01), often hunger } \\
\text { (G02), often urination (G03), } \\
\text { weight loss (G04), family } \\
\text { offspring Diabetes Mellitus (G13), } \\
\text { fatigue (G06), blurred eyes (G07), } \\
\text { pins and needles (G08), hives } \\
\text { (G09), ulcers purulent boils (G10), } \\
\text { impotence (M) / vaginal discharge } \\
\text { (F)(G11), infection (G12) }\end{array}$ \\
\hline $\begin{array}{l}\text { Spesific Types } \\
\text { of Diabetes } \\
\text { Mellitus (P04) }\end{array}$ & $\begin{array}{l}\text { Often thirsty (G01), often hungry } \\
\text { (G02), often urination (G03), often } \\
\text { consumption of steroid drugs } \\
\text { (G19), infections (G12) }\end{array}$ \\
\hline
\end{tabular}

Table 2. Decision Table

\begin{tabular}{|l|c|c|c|c|}
\hline \multirow{2}{*}{$\begin{array}{c}\text { Symptoms } \\
\text { Code }\end{array}$} & \multicolumn{4}{|c|}{ Disease Code } \\
\hline & P01 & P02 & P03 & P04 \\
\hline G01 & $*$ & $*$ & $*$ & $*$ \\
\hline G02 & $*$ & $*$ & $*$ & $*$ \\
\hline G03 & $*$ & $*$ & $*$ & $*$ \\
\hline G04 & $*$ & $*$ & $*$ & \\
\hline G05 & $*$ & & & \\
\hline G06 & $\sqrt{ }$ & $\sqrt{ }$ & $\sqrt{ }$ & \\
\hline G07 & $\sqrt{ }$ & $\sqrt{ }$ & $\sqrt{ }$ & \\
\hline G08 & $\sqrt{ }$ & & $\sqrt{ }$ & \\
\hline G09 & $\sqrt{ }$ & & $\sqrt{ }$ & \\
\hline G10 & $\sqrt{ }$ & & $\sqrt{ }$ & \\
\hline G11 & $\sqrt{ }$ & & $\sqrt{ }$ & \\
\hline G12 & $\sqrt{ }$ & & $\sqrt{ }$ & $\sqrt{ }$ \\
\hline G13 & $\sqrt{ }$ & & $*$ & \\
\hline G14 & & $*$ & & \\
\hline G15 & & $*$ & & \\
\hline G16 & & $\sqrt{ }$ & & \\
\hline G17 & & $\sqrt{ }$ & & \\
\hline G18 & & $\sqrt{ }$ & & \\
\hline G19 & & & & $*$ \\
\hline
\end{tabular}

Table 3. Rule base

\begin{tabular}{|c|c|}
\hline Disease & $\begin{array}{l}\text { Rule Base } \\
\end{array}$ \\
\hline $\mathrm{R} 1$ & $\begin{array}{l}\text { IF G01 AND G02 AND G03 AND G04 } \\
\text { AND G05 AND G06 AND G07 AND } \\
\text { G08 AND G09 AND G10 AND G11 } \\
\text { AND G12 AND G13 THEN P01 }\end{array}$ \\
\hline R2 & $\begin{array}{l}\text { IF G01 AND G02 AND G03 AND G14 } \\
\text { AND G15 AND G16 AND G17 AND } \\
\text { G06 AND G07 AND G18 THEN P02 }\end{array}$ \\
\hline R3 & $\begin{array}{l}\text { IF G01 AND G02 AND G03 AND G04 } \\
\text { AND G13 AND G06 AND G07 AND } \\
\text { G08 AND G09 AND G10 AND G11 } \\
\text { AND G12 THEN P03 }\end{array}$ \\
\hline R4 & $\begin{array}{l}\text { IF G01 AND G02 AND G03 AND G19 } \\
\text { AND G12 THEN P04 }\end{array}$ \\
\hline
\end{tabular}

\footnotetext{
* Corresponding author: devinawang4@gmail.com
}

To calculate energy requirement in one day using the equation 1 and equation 2 .

$$
\begin{aligned}
& \text { Man }=30 \times \text { Ideal weight } \\
& \text { Women }=25 \times \text { Ideal weight }
\end{aligned}
$$

To determine the value of ideal weight with the equation 3 . If men with a height of less than $160 \mathrm{~cm}$ and women less than $150 \mathrm{~cm}$ with equation 4 .

$$
\begin{aligned}
& \text { Ideal weight }=(\text { Height }-100) \times 90 \% \times 1 \mathrm{~kg} \\
& \text { Ideal weight }=(\text { Height }-100) \times 1 \mathrm{~kg}
\end{aligned}
$$

The calculation results are then adjusted for age correction factor, weight category and activity category. Addition or reduction of the energy requirement adjusted to the state of the patient based on the reference factor of the correction. The addition of age correction factors to determine the energy requirements of patients can be seen in Table 4 [12].

Table 4. Age correction factor

\begin{tabular}{|l|l|}
\hline \multicolumn{1}{|c|}{ Age } & \multicolumn{1}{c|}{ Age Factor } \\
\hline $40-59$ years & $-5 \%$ \\
\hline $60-69$ years & $-10 \%$ \\
\hline$>70$ years & $-20 \%$ \\
\hline
\end{tabular}

The addition of a weight correction factor to determine energy requirements is shown in Table 5 [12].

Table 5. Weight correction factor

\begin{tabular}{|l|l|}
\hline \multicolumn{1}{|c|}{ Category } & \multicolumn{1}{|c|}{ Weight Factor } \\
\hline Thin $(\mathrm{BMI}<18,5)$ & $+30 \%$ \\
\hline Fat $(\mathrm{BMI}>23)$ & $-30 \%$ \\
\hline
\end{tabular}

In the determination of the category of Thin and Fat categories using the Body Mass Index (BMI) which can be seen in equation 5 [12].

$$
B M I=\frac{\text { Weight }}{\text { Heightz }}
$$

Where BMI is the Body Mass Index $\left(\mathrm{kg} / \mathrm{m}^{2}\right)$, where the weight is in kilograms $(\mathrm{kg})$ and the height of the body is in meters $(\mathrm{m})$. While the additional activity correction factor to determine the energy requirement can be seen in Table 6 [12].

Table 6. Activity correction factor

\begin{tabular}{|l|l|}
\hline \multicolumn{1}{|c|}{ Activity } & \multicolumn{1}{c|}{ Factor } \\
\hline Rest activity & $+10 \%$ \\
\hline Easy activity & $+20 \%$ \\
\hline Normal activity & $+30 \%$ \\
\hline Heavy activity & $+40 \%$ \\
\hline Very heavy activity & $+50 \%$ \\
\hline
\end{tabular}

In general, the food with the number of calories calculated and the composition of the above is divided 
into 5 portions for breakfast, lunch, dinner, and 2 portions for snacks. But changes in the type, schedule and amount of food may change according to the patient's condition [12].

\subsection{Design}

Design is the third stage, which makes the design of the system as a picture of the system programming. The design stage is illustrated in the flow diagram shown in Figure 1.

\subsection{Testing}

Testing is the fourth stage. Testing on the system is done by testing the logic flow and validation of system data directly tested to the expert, as well as ensuring that the decision-making method applied runs accordingly.

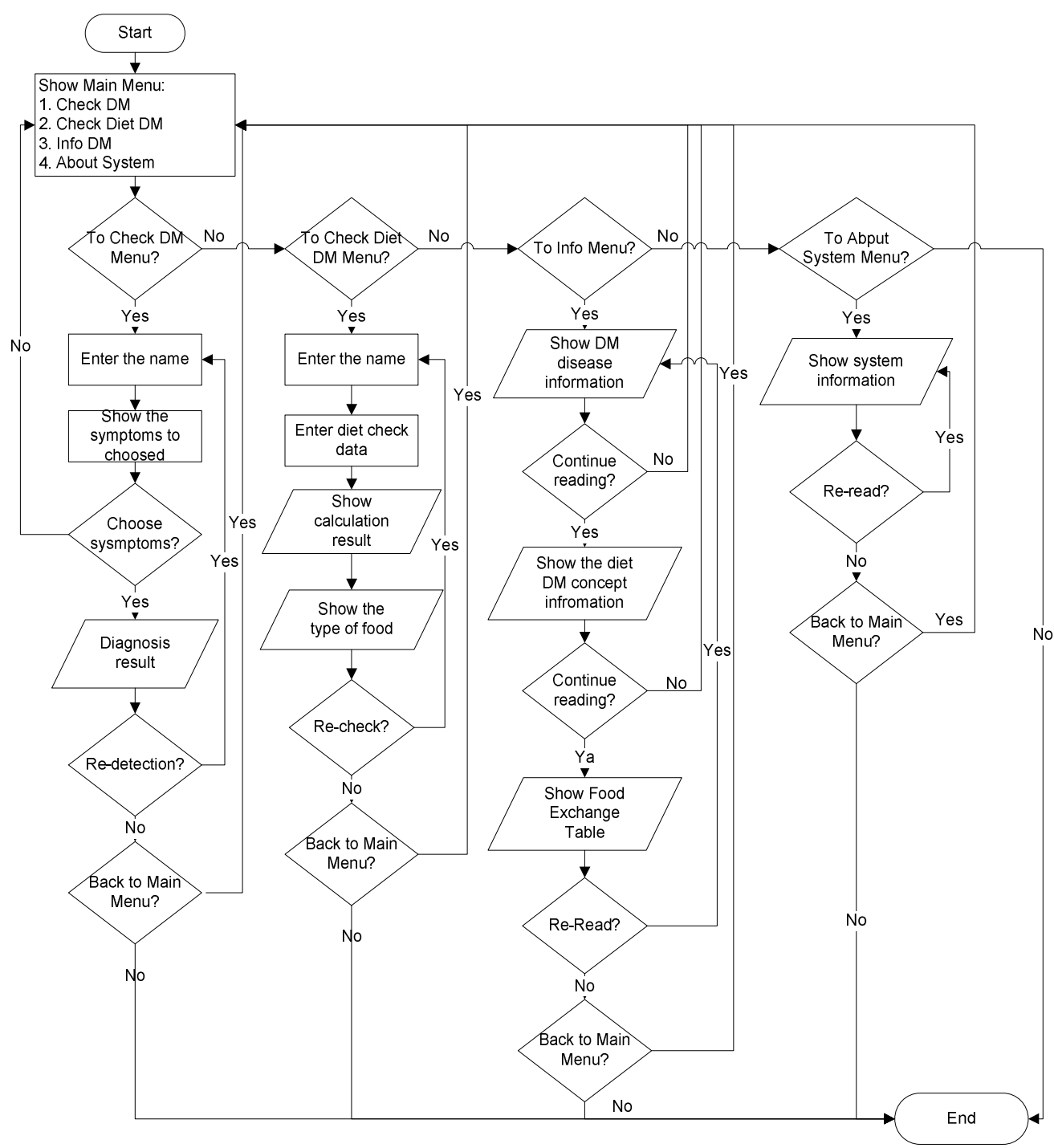

Fig. 1. Flowchart System

\section{Result and discussion}

In this study, an expert system was created for the purposes of diagnosis and determination of dietary patterns in Diabetes Mellitus patients. The expert system can be used to diagnose Diabetes Mellitus disease according to the symptoms that patients' experienced and can be used to determine the patient's diet pattern. This system is implemented on mobile devices with the Android operating system.

\footnotetext{
Corresponding author: devinawang4@,gmail.com
}

Input on the expert system are symptoms of disease, sex, weight, height, age, activity category. Symptoms of the disease include often thirsty, often hunger, often urination, weight loss, fatigue, blurred eyes, pins and needles, hives, ulcres, impotence (M)/ vaginal discharge $(\mathrm{F})$, infection, Diabetes Mellitus family offspring, age between 0-14 years, often consumption of steroid drugs, sugar during pregnancy, has a history of giving birth to a large baby. Then the input is processed using forward chaining method and produce a system with the output of Diabetes Mellitus diagnosis and determination of diet pattern in patient. 
This system consists of 4 menus, Check DM Menu, Diet DM Menu, Info Menu, and About System Menu. Check DM Menu is used to display the diagnosis page of Diabetes Mellitus based on symptoms. In the Check DM Menu contains the choice of symptoms experienced by patients in the form of questions. Users must answer all the symptoms questions displayed then the system will show the results of type Diabetes Mellitus disease experienced by the user.

The Diet DM Menu is used to display the dieting system page of the patient. In Diet DM Menu contains Form Name, Age, Height, Weight and Category Activity. Users must fill out all forms on Diet DM Menu page to calculate the amount of energy required by the patient. The amount of energy is referred to in the determination of food that can be consumed by the patient.

Info Menu is used to display information page about Diabetes Mellitus, while About System Menu is used to display page about system information. Interface system on Check DM Menu and Diet DM Menu can be seen in Figure 2 and Figure 3.

For the validation of the system performed tests with experts namely Internists and Nutritionists at Pemalang Hospital. The validation results state that the system is running correctly.

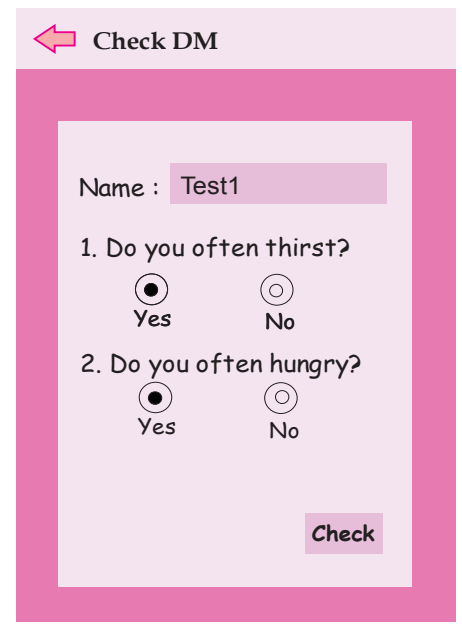

Fig. 2. Interface of Menu Check DM

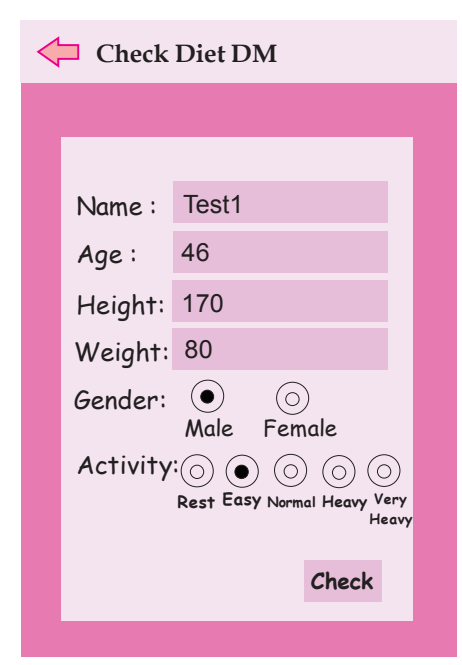

Fig. 3. Interface of Menu Diet DM

\section{Conclusion}

The result of this development is a system for diagnosing and managing the determination of patient diet patterns that can be implemented on mobile devices with the Android operating system. By using the method of forward chaining this system can be used to diagnose diseases according to Type Diabetes Mellitus based on symptoms experienced by the patient. The system also features a diet plan based on the patient's needs. System validation results show that the system is running in accordance with the logic flow of the expert. The system can also be used to manage self-control in the determination of dietary patterns of food that can be consumed by patients.

\section{References}

1. R. Meza-Palacios, A. A. Aguila-Lassere, E. L. Urena-Bogarin, C. F. Vazquez-Rodriguez, R. Posada-Gomez, A. Trujillo-Mata, Expert System with Application 72, 335 (2016)

2. J. Giarrantano, G. Riley, Expert Systems : Principle and Programming (Thomson Course Technology, Boston, 2005)

3. P. Povalej Brzan, E. Rotman, M. Pajnkihar, P. Klanjsek, J. Med Syst 40, 210 (2016)

4. M. Singh, N. Jain, Wireless Pers Commun, 1 (2015)

5. F. Basciftci, O. Faruk Hatay, Computer in Biology and Medicine 41, 350 (2011)

6. S. E. Taylor, Health Psychology (McGraw-Hill, Boston, 2006)

7. American Diabetes Association, The Journal of Clinical and Applied Research and Education 41, 1 (2018)

\footnotetext{
* Corresponding author: devinawang4@gmail.com
} 
8. PERKENI, Konsensus Pengelolaan Pencegahan Diabetes Mellitus Tipe 2 di Indonesia (PB. Perkeni, Jakarta, 2015)

9. R. E. Glasgow, P. A. Nutting, Diabetes (Oxford University, New York, 2004)

10. J. L. Sievenpiper, C. B. Chan, P. D. Dworatzek, C. Freeze, S. L. Williams, Can. J. Diabetes 42, 64 (2018)

11. A. B. Evert, J. L. Boucher, M. Cypress, S. A. Dunbar, M. J. Franz, E. J. Mayer-Davis, J. J. Neumiller, R. Nwankwo, C. L. Verdi, P. Urbanski, W. S. Yancy, Diabetes Care 37, 1 (2014)

12. I. Aritonang, Manajemen Asuhan Gizi (Leutikabooks, Yogyakarta, 2017)

* Corresponding author: devinawang4@gmail.com 